\title{
Placenta Previa Accreta Spectrum: Cesarean Hysterectomy
}

\author{
Satoru Takeda, MD, $\mathrm{PhD}^{1,2}$ Jun Takeda, MD, $\mathrm{PhD}^{1}$ \\ 1 Department of Obstetrics and Gynecology, Faculty of Medicine, \\ Juntendo University, Tokyo, Japan \\ 2 Aiiku Research Institute for Maternal, Child Health and Welfare, \\ Imperial Gift Foundation Boshi-Aiiku-Kai, Tokyo, Japan \\ ${ }^{3}$ Department of Obstetrics and Gynecology, Nerima Hikarigaoka \\ Hospital, Tokyo, Japan
}

Surg J 2021;7(suppl S1):S28-S37.
Yoshihiko Murayama, MD, $\mathrm{PhD}^{3}$

\begin{abstract}
Address for correspondence Satoru Takeda, MD, PhD, Department of Obstetrics and Gynecology, Faculty of Medicine, Juntendo University, 2-1-1, Hongo, Bunkyo-ku, Tokyo, 113-8421, Japan

(e-mail: stakeda@juntendo.ac.jp).
\end{abstract}

\begin{abstract}
Keywords

- bladder invasion

- cesarean hysterectomy

- massive hemorrhage

- placenta accreta spectrum

- placenta previa percreta

- previous cesarean section

When cesarean hysterectomy is scheduled in cases of placenta previa accreta/increta/percreta, it is necessary that the departments of obstetrics, anesthesiology, blood transfusion, urology, and radiology hold a preoperative conference to assure full preparation for the surgery. A ureteral stent inserted just before cesarean section serves as a marker. A uterine incision should be made at a site free of placental contact. The presence/absence of bladder invasion by villi, adhesions, and the degree of vascularization greatly influence the amount of bleeding, and bleeding control is a key point. For prevention of massive hemorrhage, methods of blood flow blockage, such as balloon occlusion catheterization of the aorta or common iliac artery, should be considered. Stored autologous blood and Cell Saver should be prepared. When hysterectomy is performed with the placenta left in situ, handling of the elongated cardinal ligament, ureteric injury, and bladder injury are important issues because the lower uterine segment is enlarged with the placenta. If blood flow is not blocked, separation of the bladder at the area of placenta percreta should be performed as the last step, to reduce bleeding (Pelosi's method). At this time, after handling of the cardinal ligament, bladder separation can be performed more safely if the posterior vaginal wall is incised and exposed first.

In cases of placenta accreta or partial placenta accreta/increta/percreta, a diagnosis of morbidly adherent placenta may not be obtained until separation of the placenta is performed. If bleeding from the placental separation surface cannot be controlled, total hysterectomy should be performed without hesitation.
\end{abstract}

\section{Surgical Steps}

1. Laparotomy.

$\downarrow$

2. Incision in the myometrium apart from placental attachment, delivery of the fetus, and myometrial suture

$$
\downarrow
$$

published online May 25, 2021
DOI https://doi.org/ $10.1055 / \mathrm{s}-0040-1721492$ ISSN 2378-5128.
3. Cutting of the round ligament, incision and exposure of the broad ligament

$\downarrow$

4. Cutting of the proper ligament of the ovary and the fallopian tube $\downarrow$

5. Incision of the anterior and posterior lobes of the broad ligament and identification of the ureter $\downarrow$
(C) 2021. The Author(s).

This is an open access article published by Thieme under the terms of the Creative Commons Attribution-NonDerivative-NonCommercial-License, permitting copying and reproduction so long as the original work is given appropriate credit. Contents may not be used for commercial purposes, or adapted, remixed, transformed or built upon. (https://creativecommons.org/ licenses/by-nc-nd/4.0/)

Thieme Medical Publishers, Inc., 333 Seventh Avenue, 18th Floor, New York, NY 10001, USA 
6. Cutting and ligation of the uterine artery and vein and cutting and ligation of the uterosacral ligament $\downarrow$

7. Cutting and suture of the cardinal ligament $\downarrow$

8a. Pelosi's method: manual separation between the nonadherent bladder and the anterior vaginal wall $\downarrow$

8b. Posterior approach: opening of the posterior vaginal wall at first and separation of the nonadherent bladder from the anterior vaginal wall $\downarrow$

9. Separation of the adhesion site of the bladder or placenta percreta site and excision of the uterus $\downarrow$

10. Closure of the vaginal canal and hemostasis $\downarrow$

11. Drain insertion and abdominal closure

\section{Preoperative Evaluation}

\section{Examination and Diagnosis}

Placenta previa patients should be checked for the presence/ absence of morbidly adherent placenta by ultrasonography, Doppler ultrasonography, etc. High-risk patients with placenta previa with prior cesarean section require more detailed examination by magnetic resonance imaging (MRI), cystoscope, etc. (- Fig. 1). ${ }^{1,2}$ The rate of accurate diagnosis is high in cases of placenta increta and placenta percreta but low in placenta accreta cases in which villi are adherent to the myometrium. ${ }^{2}$ In particular, partial placenta accreta/ increta/percreta is often difficult to diagnose definitively.

\section{Selection of Treatment}

It is necessary to fully discuss with the patient and family members in advance whether the uterus should be excised by primary or delayed hysterectomy and whether the preservation of the uterus should be attempted. Their consent to the procedures that may be necessary at the time of emergencies, such as massive hemorrhage during surgery, should be obtained after sufficient information has been provided (-Fig. 2 ).

\section{Contraindications}

In cases in which a diagnosis of placenta previa increta/percreta has been established, the myometrium of the uterine body or fundus should be incised to deliver the fetus, with due caution to avoid cutting into the placenta. The placenta should never be separated. In addition, the incising procedure should also avoid cutting into the placenta when the myometrium in the area of placental attachment, as determined by ultrasonography, is translucent and can be seen as blue in color or when there are numerous engorged blood vessels in the myometrium on the anterior surface of the uterus and around the bladder (-Fig. $\mathbf{3}$ ). ${ }^{2}$

\section{Preoperative Preparation}

It is necessary to understand the guidelines for responses to critical hemorrhage and obstetric critical hemorrhage, and also to routinely simulate the actions to be taken for

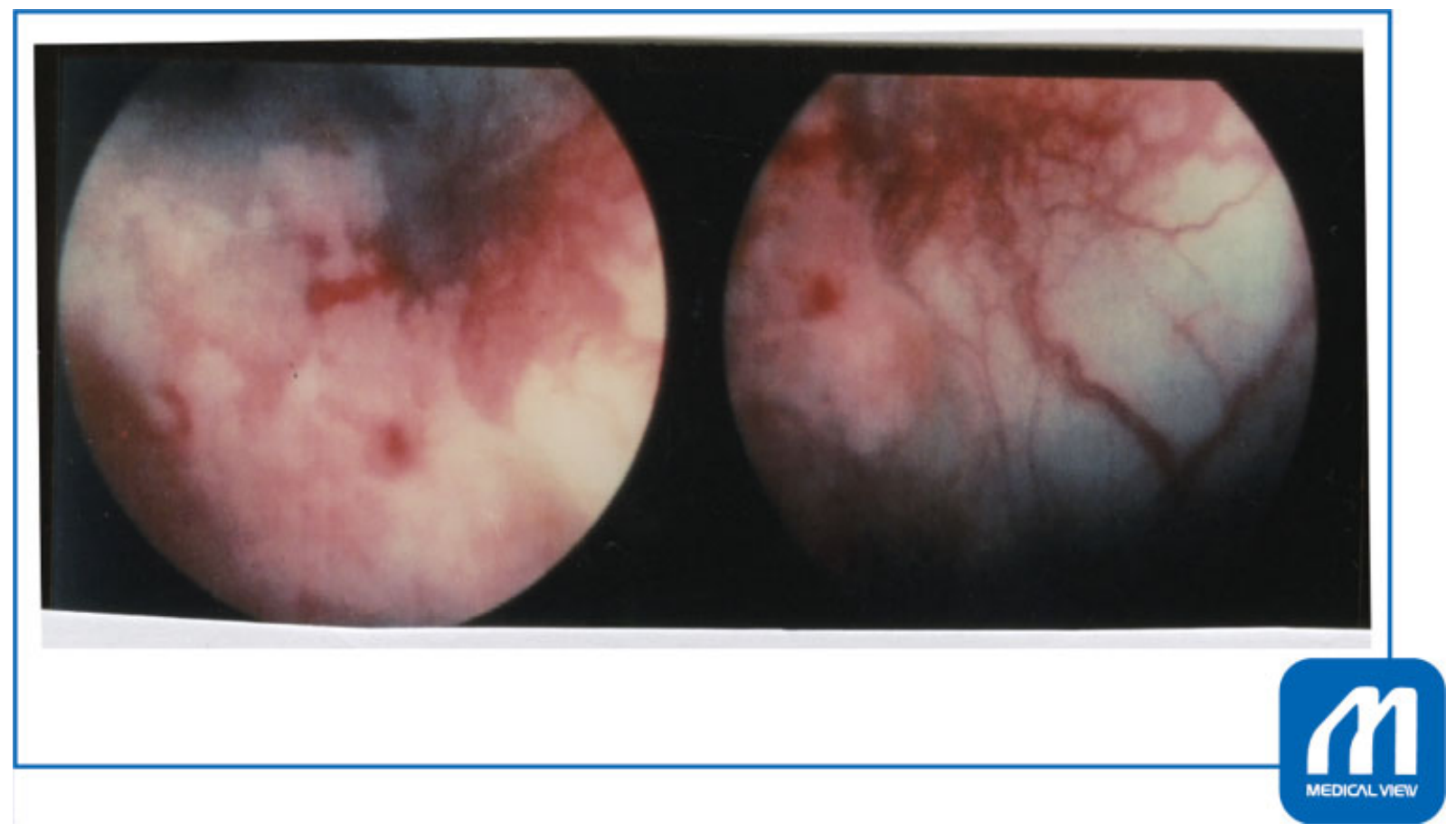

Fig. 1 Cystoscopic findings in placenta percreta. There is hematuria, and bleeding and numerous blood vessels are observed in the mucosa of the bladder. (Reproduced with permission from Takeda S. Murayama Y. Cesarean hysterectomy. In: Hiramatsu Y, Konishi I, Sakuragi N, Takeda S, eds. Surgery for pregnancy with placenta previa and placenta accrete: Careful preparation and critical management. OGS NOW, No.9. [Japanese]. Tokyo: Medical View; 2012:122-133. Copyright @ Medical View). 


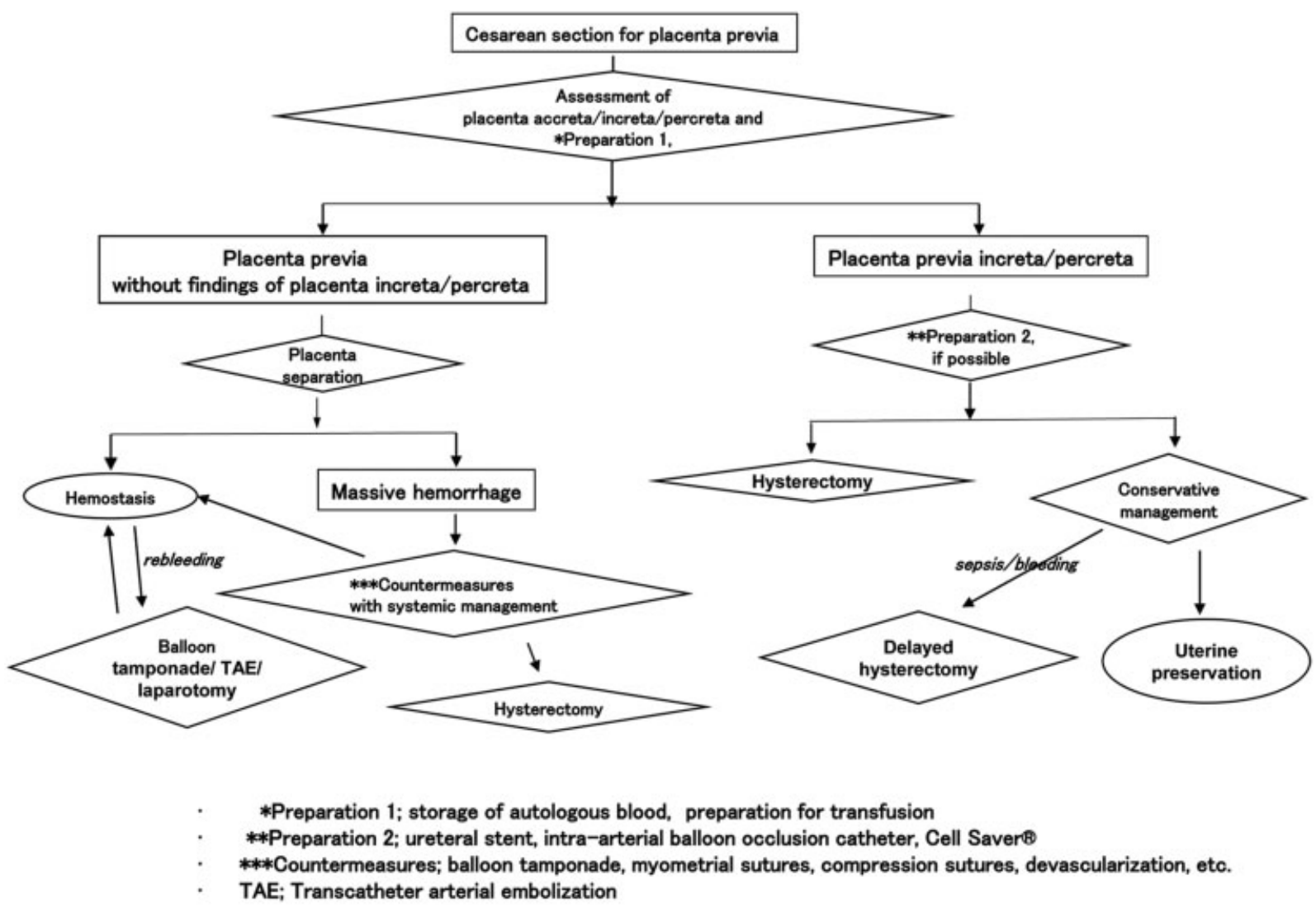

Fig. 2 Surgical strategies for placenta previa accreta spectrum and its management. (Reproduced with permission from Takeda S., Takeda J., Makino S. Cesarean section for placenta previa and placenta previa accreta spectrum. Surg J 2020; doi:10.1055/s-0039-3402036).

massive vaginal hemorrhage and intraoperative massive hemorrhage to reach a consensus among the entire hospital staff, not limited to the ward, operating rooms, and blood transfusion staff. ${ }^{2}$

A preoperative conference involving the departments of obstetrics, gynecology (if possible, doctors specialized in gynecologic oncology who have a good knowledge of the anatomy of the pelvis), anesthesiology, blood transfusion, urology, and radiology (balloon occlusion catheterization, and embolization) should be held. In the department of obstetrics, the site of incision in the myometrium of the uterine corpus, division of roles among operators, and how to respond to massive hemorrhage and spontaneous separation of a part of the placenta should be sufficiently discussed prior to the operation. Storage of autologous blood and consultation with the department of blood transfusion and the blood transfusion center regarding the stocking and securing of adequate blood supplies in cases with unexpected contingencies are necessary., ${ }^{3,4}$ For patients with type AB blood group, which is usually not stocked in large quantities, the use of not cross-matched compatible red blood cell and fresh frozen plasma should also be discussed preoperatively. ${ }^{2,4}$ Sufficient blood for transfusion should be ready on the day of surgery, also making Cell Saver available if possible.
On the day of surgery, preoperative or intraoperative ultrasonography should be performed to confirm the site of attachment of the placenta, fetal presentation, fetal attitude, and the position of presentation and to thereby decide the site of incision in the uterus.

If possible, insertion of intra-arterial balloon occlusion catheter and ureteral stent should be performed prior to the initiation of cesarean section. ${ }^{2,5}$

\section{Tips and Warnings}

In addition to the usual cesarean section operation supplies, there should be six towel roles for compression in case of massive hemorrhage and extra serrated forceps (six pairs of straight forceps and six pairs of curved forceps) disinfected and ready to use.

Serrated forceps have a strong grip force and rarely cause tissue injury when used to temporarily hold the bladder, ureter, artery, or vein. Therefore, they are useful for holding the bleeding area. 


\section{Explanation of Procedures}

\section{Laparotomy}

A midline incision in the lower abdomen is recommended to secure the field of view for hemostatic procedures and arterial ligation.

\section{Incision in the Myometrium Apart from Placental Attachment, Delivery of the Fetus, and Myometrial Suture}

When hysterectomy is scheduled, a longitudinal incision or a transverse incision in the uterine body or a transverse incision in the uterine fundus (Kotsuji's technique) should be made at a site sufficiently distant from the placenta. ${ }^{2}$ When there is the possibility of the uterus being preserved in cases of suspected placenta accreta, a transverse incision in the uterine body or a J-shaped incision should be made to facilitate hemostatic suture on the placental separation surface. After rupture of membranes and delivery of the fetus, the umbilical cord should be ligated and cut. Without separating the placenta, the myometrial incision should be sutured and closed by continuous suture as quickly as possible. $^{2}$

Massive hemorrhage due to spontaneous separation of part of the placenta or manual separation of the placenta. Hemostasis should be attempted by various procedures including gauze tamponade, suture of the bleeding area $(Z$ suture, whole myometrial $\mathbf{U}$-shaped suture, interrupted circular suture, etc.), compression suture, and arterial liga- tion. $^{2}$ If bleeding is not controllable, total hysterectomy should be performed without hesitation. ${ }^{2}$

\section{Cutting of the Round Ligament, Incision, and Exposure of the Broad Ligament}

The round ligament, oviduct, and proper ligament of the ovary should be held together bilaterally with long straight Kocher's clamps or long straight serrated forceps to pull the uterus. During manipulation of the uterus, the lower uterine segment bulged, taking on a potbelly shape, which is the site of placental attachment. This should be kept untouched as much as possible. If this is not done, it may lead to massive hemorrhage from the uterine os into the vagina during surgery. The round ligament should be picked up with Pean's forceps, and it should be ligated with absorbable thread on the medial and lateral sides and cut in between the two. The lateral side should be processed by double ligation, and the ligature should be pulled to tense the broad ligament. The peritoneum of the anterior lobe of the broad ligament should be incised in the directions toward the proper ligament of the ovary and the bladder to expose the retroperitoneal space. At this time, the suspensory ligament of the ovary should be traced cranially to identify the ureter.

\section{Cutting of the Proper Ligament of the Ovary and the Fallopian Tube}

The oviduct and vascular plexuses around the ovary should be identified, and a hole should be made with a Kelly's clamp in the avascular posterior lobe of the broad ligament beneath

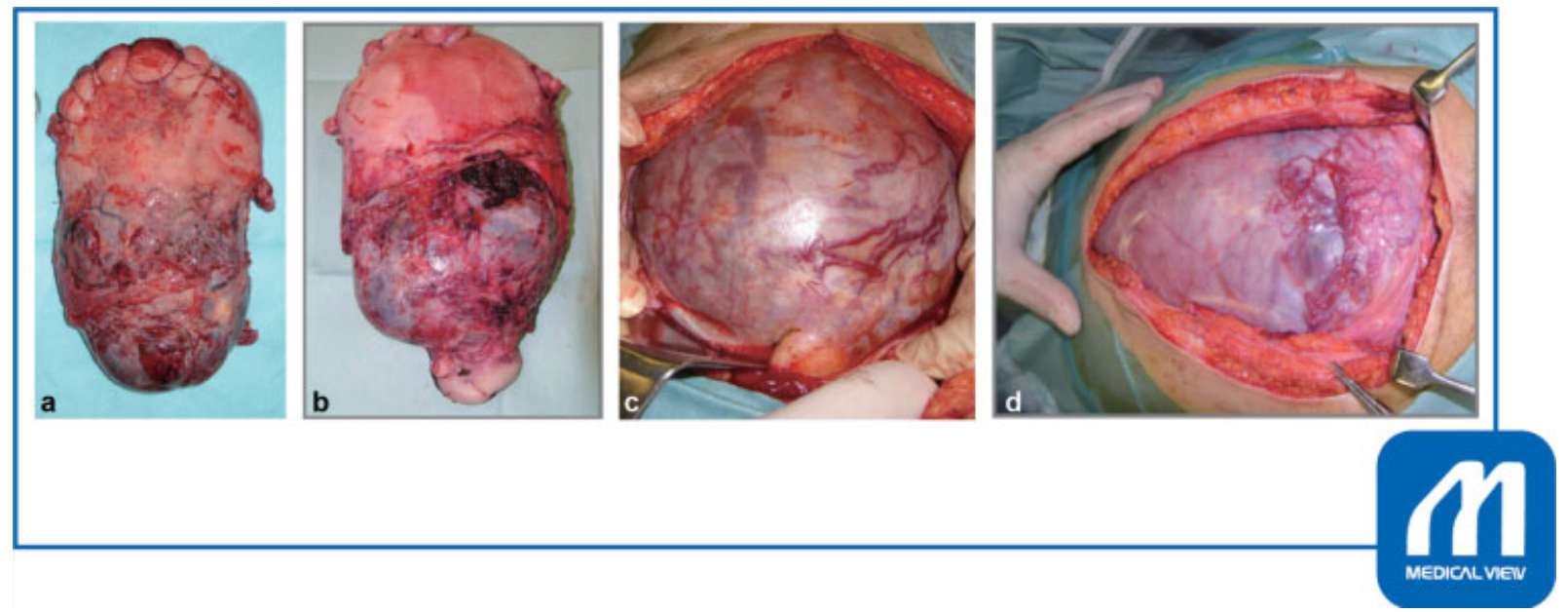

Fig. 3 Findings of uterine myometrium in placenta increta and placenta percreta. The site of attachment of the placenta in the lower uterine segment is swollen into a potbelly shape. These specimens (a, b) were obtained by hysterectomy following delivery of the fetus via a transverse incision in the uterine fundus. Many thick engorged arteries and veins on the uterine surface (c, d) were seen in cases with placenta increta during cesarean section. (Reproduced with permission from Takeda S. Murayama Y. Cesarean hysterectomy. In: Hiramatsu Y, Konishi I, Sakuragi N, Takeda S, eds. Surgery for pregnancy with placenta previa and placenta accrete: Careful preparation and critical management. OGS NOW, No.9. [Japanese]. Tokyo: Medical View; 2012:122-133. Copyright (c Medical View). (a) Excised uteri; Placenta percreta. The blood in the intervillous space at the site of attachment of the placenta is visualized as a bluish color. There are numerous markedly engorged blood vessels in the myometrium and on the surface of the uterus. The penetrating placenta is seen in the indicated area ( $\leftarrow$ ). (b) Excised uteri; Placenta increta. Similarly, the area of attachment of the placenta is seen as a having bluish color. Several arteries and veins are seen. (c, d) Uteri during cesarean section (placenta increta in both cases). In both cases, the site of attachment of the placenta appears to be bluish in color, and intervillous spaces appear translucent. There are many thick engorged arteries and veins within and on the surface of the myometrium. If these morphological features are observed on the anterior surface of the uterus following laparotomy, this part should be left untouched, while the fundus and body of the uterus are incised to deliver the fetus. Whether to excise the uterus with the placenta left unseparated or to excise the uterus by delayed hysterectomy should be decided. 


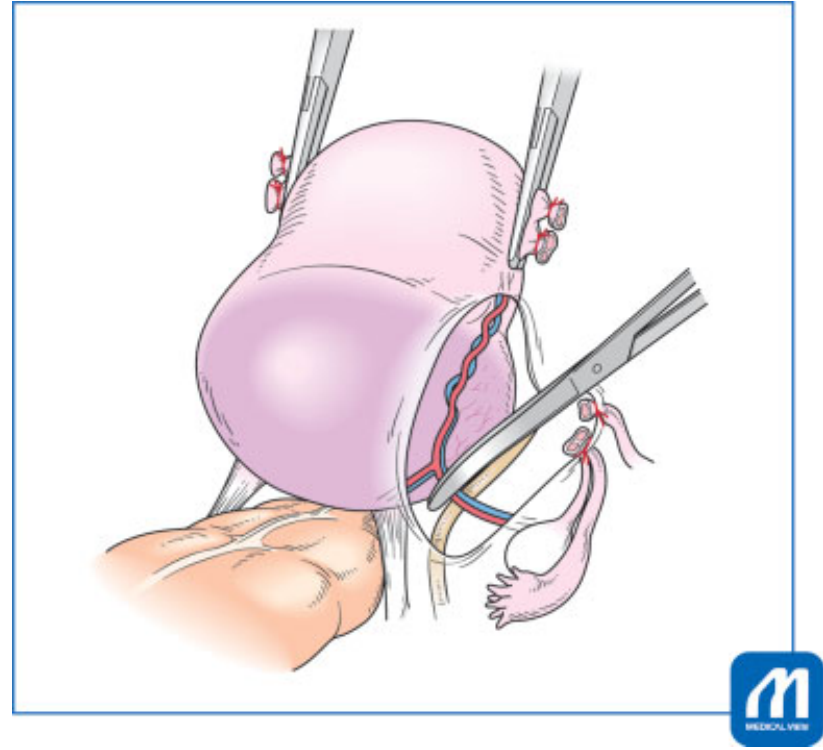

Fig. 4 Confirmation of the route of the ureter. The lower uterine segment is enlarged like a potbelly-like bulging because of the preserved placenta. Therefore, the ureter is located extremely close to the uterus. After confirming the course of the ureter from the site of uterosacral ligament attachment to the site of crossing with the uterine artery, the ureter should be separated from the lower uterine segment. (Reproduced with permission from Takeda S. Murayama Y. Cesarean hysterectomy. In: Hiramatsu Y, Konishi I, Sakuragi N, Takeda $\mathrm{S}$, eds. Surgery for pregnancy with placenta previa and placenta accrete: Careful preparation and critical management. OGS NOW, No.9. [Japanese]. Tokyo: Medical View; 2012:122-133. Copyright $\odot$ Medical View).

the vascular plexuses. The fallopian tube and the proper ligament of the ovary should be held with serrated forceps and cut at a site between the forceps. The cut end should be sutured employing either a figure-eight suture or interrupted suture. Because this procedure is a focused ligation, it is necessary to use the double ligature technique. If the cut end is close to the suture thread, and there is a risk of loosening of the ligature, Kobayashi's ligation should be added. $^{6}$ When the cut end is broad, or when there are engorged blood vessels, the fallopian tube and the proper ligament of the ovary should be ligated and cut separately. Recently tubectomy is performed for prophylaxis of the tubal origin ovarian cancer.

\section{Incision of the Anterior and Posterior Lobes of the Broad Ligament and Identification of the Ureter}

The posterior lobe of the broad ligament should be separated and incised in the direction toward the site of attachment of the uterosacral ligament to obtain a sheet of peritoneum. The location of the ureter should be definitely confirmed. The lower uterine segment is enlarged into a potbelly shape, and the ureter is close to the uterus. In this case, the ureter should be separated laterally from the uterus, and its course should then be confirmed up to the vicinity of the site of crossing with the uterine artery (-Fig. 4). This is easier if there is a ureter stent in place.

The peritoneum of the anterior lobe of the broad ligament should be incised up to a site near the bladder, and the

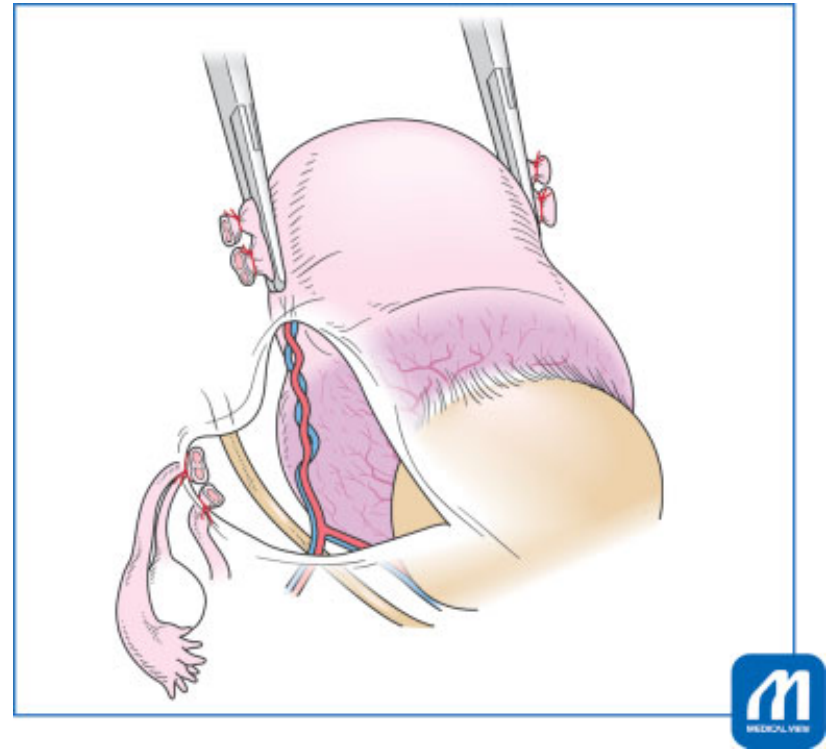

Fig. 5 Incision of the anterior lobe of the broad ligament. The bladder is often elevated and adherent to the uterus. At this time, incision of the peritoneum of the vesicouterine pouch is not indispensable, and can be omitted if it is too difficult to perform. In the lower uterine segment where there is placenta increta, the placenta is translucent and can be seen as having a blue color, and there are numerous engorged blood vessels on the uterine surface. (Reproduced with permission from Takeda S. Murayama Y. Cesarean hysterectomy. In: Hiramatsu Y, Konishi I, Sakuragi N, Takeda S, eds. Surgery for pregnancy with placenta previa and placenta accrete: Careful preparation and critical management. OGS NOW, No.9. [Japanese]. Tokyo: Medical View; 2012:122-133. Copyright @ Medical View).

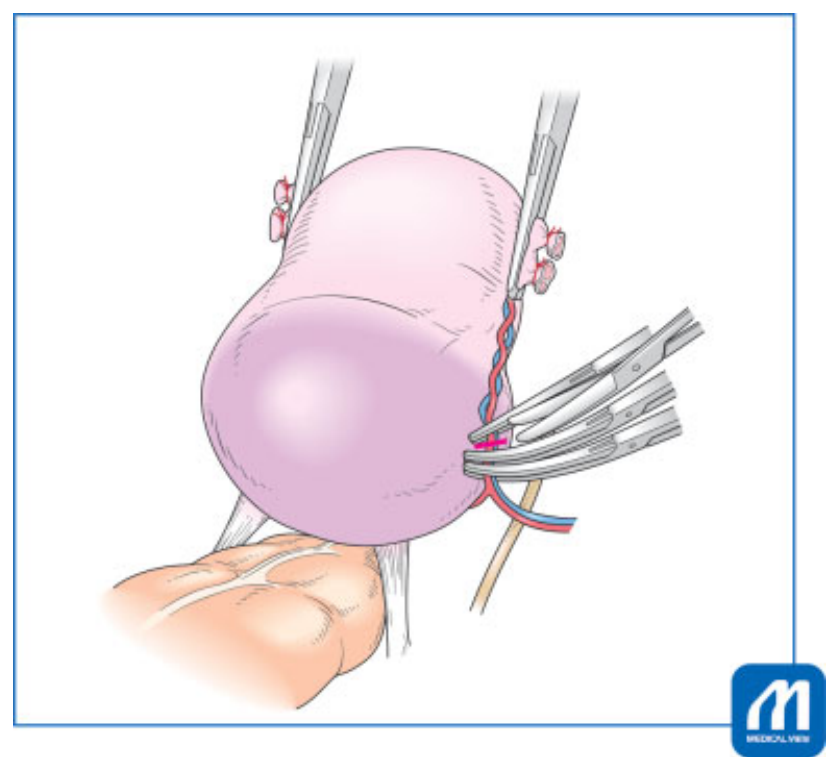

Fig. 6 Cutting and suture ligation of the uterine artery and vein. The operator should always pay attention to how close the ureter is. The cardinal ligament is increased in length and width due to the enlarged lower uterine segment. (Reproduced with permission from Takeda S. Murayama Y. Cesarean hysterectomy. In: Hiramatsu Y, Konishi I,

Sakuragi N, Takeda S, eds. Surgery for pregnancy with placenta previa and placenta accrete: Careful preparation and critical management. OGS NOW, No.9. (Japanese). Tokyo: Medical View; 2012:122-133. Copyright $\odot$ Medical View). 
peritoneum of the vesicouterine pouch should also be incised (-Fig. 5). If blood vessels around the bladder are engorged or when the bladder is firmly adherent to the uterus and elevated, the peritoneum of the vesicouterine pouch should be left untouched without incision. At this stage, the bladder should never be separated; bladder separation will be performed in the last step.

\section{Cutting and Ligation of the Uterine Artery and Vein and Cutting and Ligation of the Uterosacral Ligament} The parametrium should be separated and cut employing an electric cautery device, allowing the courses of the uterine artery and vein to be confirmed. In addition, the course of the ureter should also be confirmed, as well as the site of crossing with the uterine artery and vein. At this crossing site, the uterine artery and vein may be picked up with a Kelly's clamp to ligate the main stem of the uterine artery.

Because the bladder is not separated, connective tissue located lateral to the bladder and anterior to the cardinal ligament should be sufficiently separated. At a site 2 to $3 \mathrm{~cm}$ distant from the ureter, the uterine artery and vein and the upper part of the carinal ligament should be held with two pairs of curved serrated forceps, and with a straight Kocher's clamp on the uterine side while aligning the tips (-Fig. 6). The uterine artery and vein should be cut between the Kocher clamp and the serrated forceps, and incised up to the tip of the lower serrated forceps. Suture ligature of the uterine artery and vein should be performed with 1-0 absorbable thread at the tip of the lower forceps. Then, suture ligature should be performed similarly at the tip of the upper forceps to achieve double ligature of the uterine artery and vein. If there is a sufficient margin in the cut end on the uterine side, suture ligation should also be performed. Minimizing forceps use on the uterine side is preferable. If forceps on the uterine side are released, massive hemorrhage will result.

The uterosacral ligament should be held with long-curved serrated forceps, cut, and suture ligated. When cutting the cardinal ligament, the cut end of the uterosacral ligament serves as a marker for clamping of the posterior portion of the cardinal ligament because the cutting manipulation proceeds medially to the cut end of the uterosacral ligament (-Fig. 7). The uterosacral ligament should be severed following one or two manipulations to achieve the cutting and ligation of the cardinal ligament.

\section{Tips and Warnings}

Clamping on the uterine side is not necessary in routine total hysterectomy cases. However, in cases of cesarean hysterectomy, bleeding from the uterine side may be massive, unless there is processing of the cut end because uterine blood flow is abundant. Therefore, clamping or suture ligation on the uterine side is required. Forceps used for clamping may impede procedures or may even be released accidentally to cause bleeding during manipulation; caution is therefore necessary. If the forceps are

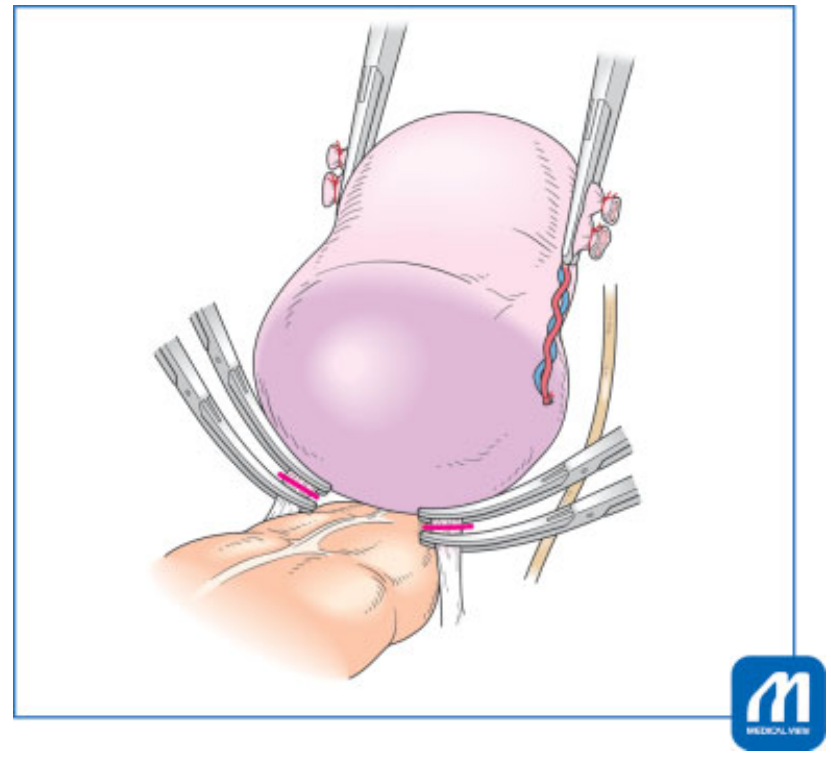

Fig. 7 Cutting and suture ligation of the uterosacral ligament. When the uterosacral ligament is severed in advance, the cut end serves as a marker for the direction of cardinal ligament sectioning. The section line proceeds medially to the cut end. (Reproduced with permission from Takeda S. Murayama Y. Cesarean hysterectomy. In: Hiramatsu Y, Konishi I, Sakuragi N, Takeda S, eds. Surgery for pregnancy with placenta previa and placenta accrete: Careful preparation and critical management. OGS NOW, No.9. [Japanese]. Tokyo: Medical View; 2012:122-133. Copyright (@) Medical View).

left for clamping, a sufficient tissue margin should be left on the uterine side to avoid release of the forceps when cutting the tissue. Because the grip force of forceps is stronger at the tip portion because of the mechanics of forceps, it is recommended that a larger margin of tissue be left near the root of the blade.

\section{Cutting and Suture of the Cardinal Ligament}

Because the lower uterine segment bulges, taking on a potbelly shape, the cardinal ligament is thickened and elongated. Therefore, caution is necessary not to cut an excessive amount. Because the ureter is located extremely close to the uterus, the cutting manipulation should proceed by confirming the course of the ureter or the placement of the stent. When cutting the cardinal ligament (parametrium), clamping on the uterine side is also necessary to prevent bleeding from the uterine side ( $\mathbf{- F i g . ~} \mathbf{8}$ ). Cutting and suture of the cardinal ligament are implemented in three or more installments. Because the uterus and the bladder on the midline are not separated, cutting of the cardinal ligament should be performed while separating the connective tissue located lateral to the bladder and anterior to the cardinal ligament. The remaining portion of the cardinal ligament should be cut and suture-ligated by confirming the course of the ureter, though palpation of the stent in the ureter. 


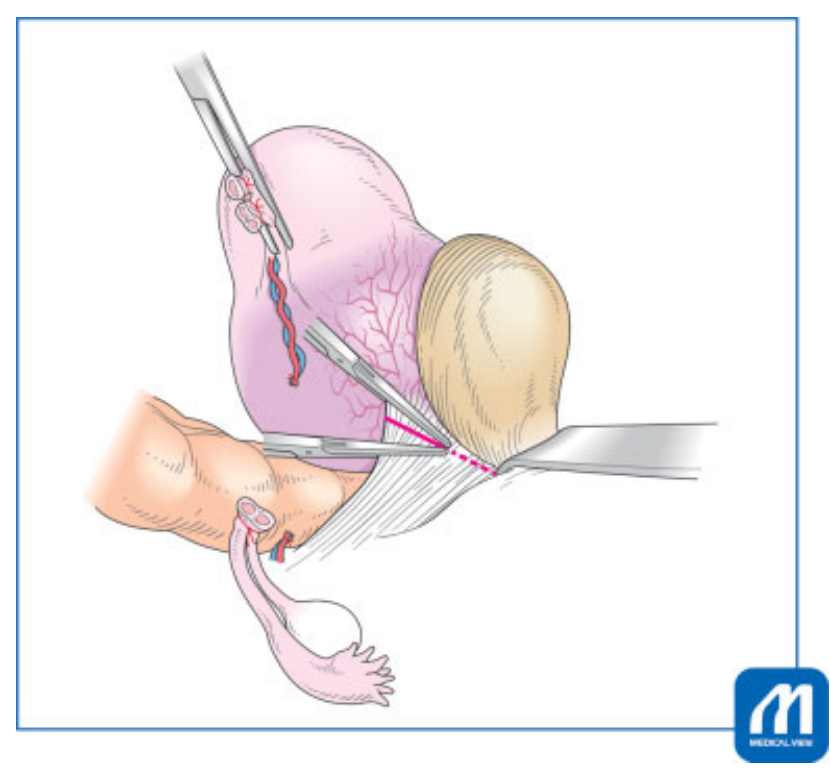

Fig. 8 Cutting of the cardinal ligament. While leaving the adherent bladder as it is, the cardinal ligament should be cut. Connective tissue around the bladder and anterior to the cardinal ligament should be separated sufficiently and cut to open the upper part of the paravesical space. The lower uterine segment is enlarged like cervical myoma. Therefore, the cardinal ligament is thickened and elongated. The cardinal ligament should thus be cut in three or more steps without cutting an excessive amount at one time. Thus, the cutting and suture ligation procedures should be performed steadily. Attention should be paid to the course of the ureter passing from behind the cardinal ligament through the tunnel part. (Reproduced with permission from Takeda S. Murayama Y. Cesarean hysterectomy. In: Hiramatsu Y, Konishi I, Sakuragi N, Takeda S, eds. Surgery for pregnancy with placenta previa and placenta accrete: Careful preparation and critical management. OGS NOW, No.9. [Japanese]. Tokyo: Medical View; 2012:122-133. Copyright @ Medical View).

\section{Pelosi Method: Manual Separation between the Nonadherent Bladder and the Anterior Vaginal Wall} In cases with insertion of an arterial balloon occlusion catheter, when there is bleeding from around the bladder or massive uterine hemorrhage, blood flow should be blocked, as needed, by the occlusion catheter. If there is no bleeding, blood flow is blocked before separation of the bladder. Blockage should last for at least 40 minutes, possibly up to 1 hour. If blockage over an extended time period is necessary, blood flow should be released once and then blocked again. If the blood flow of the common iliac artery (flow to the lower limbs) is to be blocked, unfractionated heparin 3,000 to 5,000 units $(60-100$ units $/ \mathrm{kg}$ ) should be infused intravenously in advance. ${ }^{5}$

After blocking blood flow, the bladder should be pinched and elevated manually, and the bladder should be separated from the uterine wall by using an electric cautery device ( - Fig. 9). Blood vessels should be cut and ligated, and ligation should be performed at bleeding points. When there is massive hemorrhage, pressure hemostasis should be employed with a towel while implementing the separation procedure.

In cases of placenta percreta or firm adhesion of the bladder, the area of adhesion should not be touched. Manual separation between the nonadherent bladder in a lower

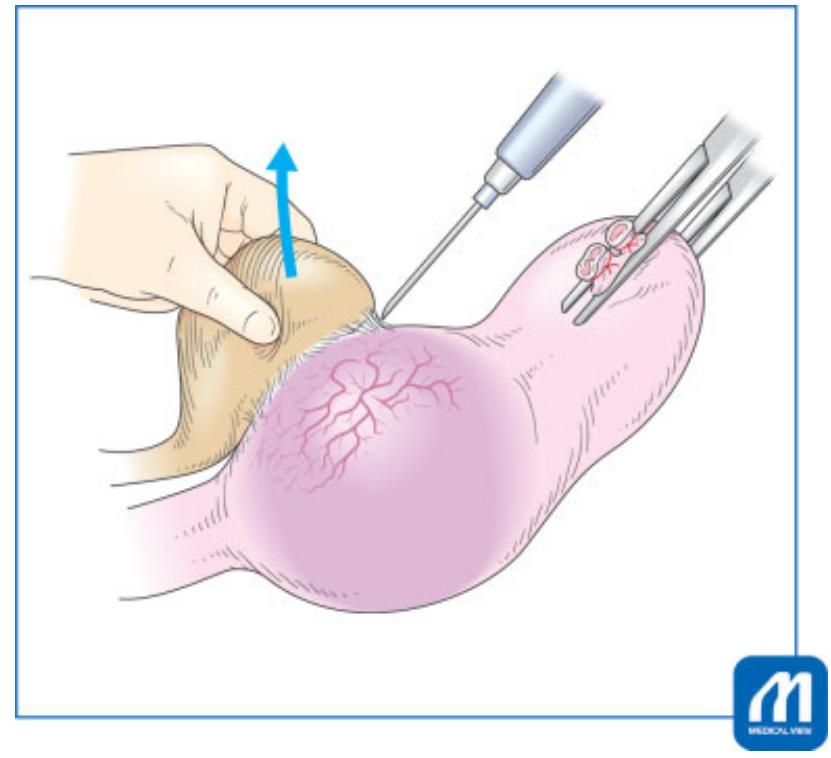

Fig. 9 Separation of the bladder. If an arterial balloon occlusion catheter is in place, blood flow should be blocked at this point to initiate separation of the bladder. The bladder should be pinched and elevated $(\uparrow)$, and separated quickly using an electric cautery device. Blood vessels should be ligated as much as possible, and bleeding from the surface should be controlled by applying towel pressure to facilitate quick separation. (Reproduced with permission from Takeda S. Murayama Y. Cesarean hysterectomy. In: Hiramatsu Y, Konishi I, Sakuragi N, Takeda S, eds. Surgery for pregnancy with placenta previa and placenta accrete: Careful preparation and critical management. OGS NOW, No.9. [Japanese]. Tokyo: Medical View; 2012:122-133. Copyright $\odot$ Medical View).

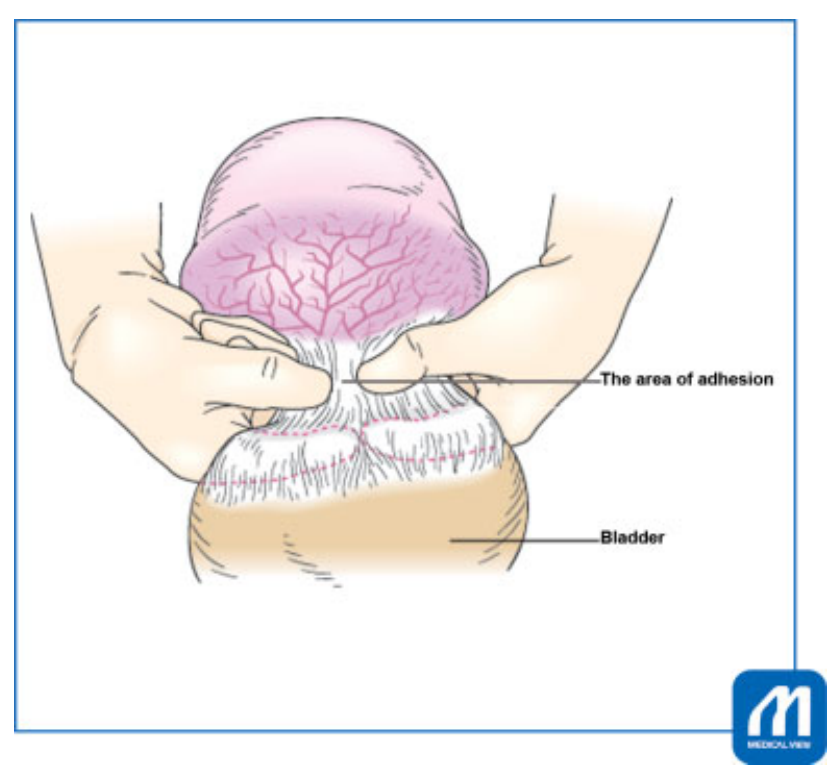

Fig. 10 Pelosi method. When blood flow cannot be blocked after a major part of the cardinal ligament is cut or when adhesions are extensive in placenta percreta cases, separation of the bladder should be performed in the last step. (Reproduced with permission from Takeda S. Murayama Y. Cesarean hysterectomy. In: Hiramatsu Y, Konishi I, Sakuragi N, Takeda S, eds. Surgery for pregnancy with placenta previa and placenta accrete: Careful preparation and critical management. OGS NOW, No.9. [Japanese]. Tokyo: Medical View; 2012:122-133. Copyright @ Medical View). 
portion and the anterior vaginal wall and /or the uterine cervix should be performed, and the vaginal canal should be clamped from the right and left sides. After completely blocking blood flow, the area of adhesion between the bladder and the uterus should, finally, be cut ( $\mathbf{- F i g . 1 0})^{2,7}$

\section{Posterior Approach: Opening of the Posterior Vaginal Wall at First and Separation of the Nonadherent Bladder from the Anterior Vaginal Wall}

This procedure is a modified Pelosi's method by which separation of the part of the bladder with penetration is implemented in the last step. This is a method of hemostasis used in cases without an occlusion catheter in place. ${ }^{1}$ Because the lower uterine segment bulges into a potbelly shape, it is often unclear to what extent the cutting of the cardinal ligament should proceed. In this regard, after performing the cutting manipulation once or twice, we insert long curved Pean's forceps from the vagina toward the posterior vaginal fornix. Using the forceps as a guide, the posterior vaginal wall is incised and opened in advance.

First, manual separation between the nonadherent vaginal wall and the lower part of the bladder inferior to the site of the placenta percreta should be performed to make a tunnel. The vaginal wall should be held with large curved forceps from the right and left sides, and the blood flow from the vagina should be blocked. Finally, the bladder is separated from the uterus.

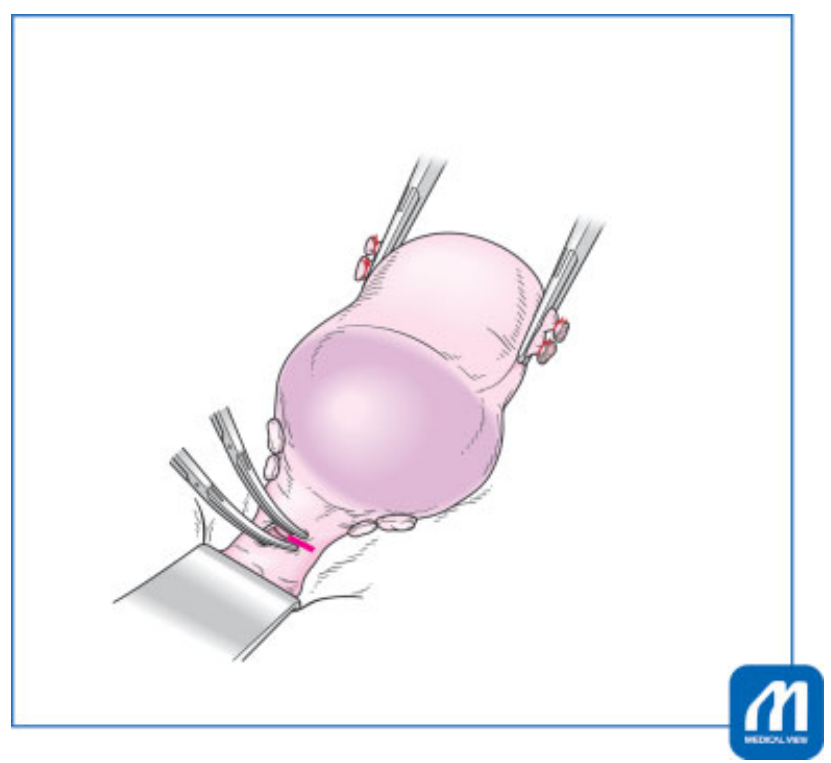

Fig. 11 Incision and opening of the posterior vaginal wall (Posterior view of the uterus). The modified Pelosi method by which the posterior vaginal wall is incised and opened in advance to facilitate safe implementation of the cutting of the cardinal ligament and separation between the bladder and the vaginal wall. It is possible to insert a finger in the vagina to palpate the remaining portion of the cardinal ligament and to guide the separation between the bladder and the vaginal wall. (Reproduced with permission from Takeda S. Murayama Y. Cesarean hysterectomy. In: Hiramatsu Y, Konishi I, Sakuragi N, Takeda S, eds. Surgery for pregnancy with placenta previa and placenta accrete: Careful preparation and critical management. OGS NOW, No.9. [Japanese]. Tokyo: Medical View; 2012:122-133. Copyright $\odot$ Medical View).

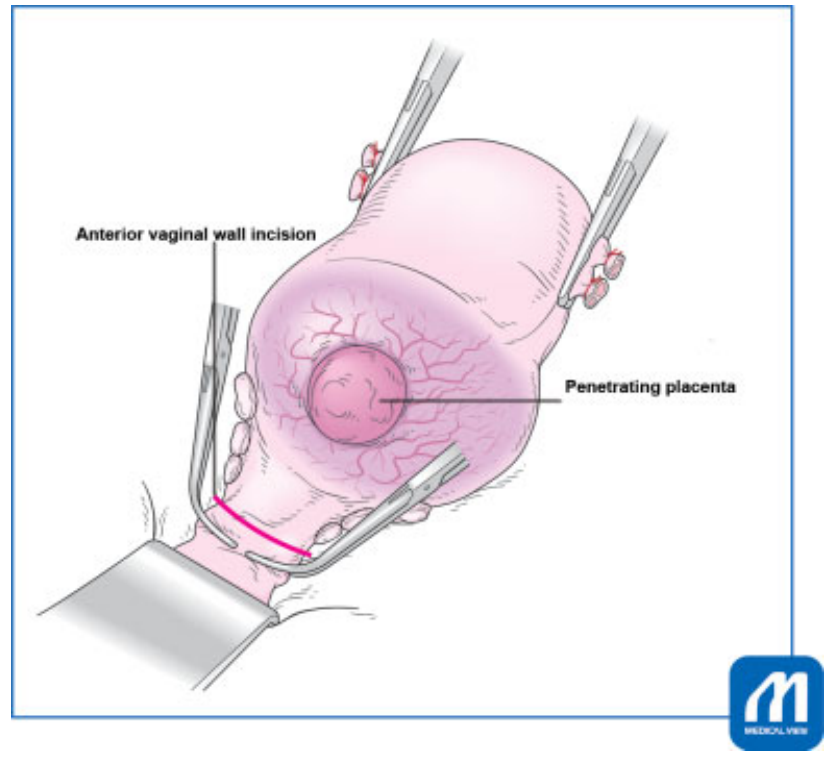

Fig. 12 Cutting of the vaginal wall (Anterior view of the uterus). When the posterior vaginal wall incision procedure is used, the anterior vaginal wall alone is severed. (Reproduced with permission from Takeda S. Murayama Y. Cesarean hysterectomy. In: Hiramatsu Y, Konishi I, Sakuragi N, Takeda S, eds. Surgery for pregnancy with placenta previa and placenta accreta: Careful preparation and critical management. OGS NOW, No. 9. [Japanese]. Tokyo: Medical View; 2012:122-133. Copyright (® Medical View).

Two pairs of serrated curved forceps should be inserted from the incision to hold the posterior vaginal wall. The posterior vaginal wall should be cut between the forceps, and processed employing a $\mathbf{U}$-shaped suture. This manipulation should proceed to the left and right to completely expose the posterior vaginal wall (-Fig. 11). Exposing the posterior vaginal fornix in advance allows us to easily palpate and understand the remaining part of the cardinal ligament, and to perform separation of the bladder and anterior vaginal wall without difficulty.

A finger should be inserted from the opened posterior vaginal wall to identify the anterior vaginal fornix. Targeting that site, with a finger inserted medial to the ureter stent and posterior to the bladder, the bladder should be separated from the anterior vaginal wall. When a penetration passage is formed like a tunnel between the right and left sides, the anterior vaginal wall and the remaining paravaginal wall and parametrium should be held with large curved serrated forceps to block the blood flow from the direction of the vagina. This method is advantageous in that it allows safe and easy separation between the bladder and the vaginal wall or the anterior surface of the uterus.

\section{Separation of the Adhesion Site or Placenta Percreta Site and Excision of the Uterus}

When cutting the adhesion between the bladder and the uterus using an electric cautery device or other equipment, it is helpful to elevate the bladder to add tension to the site of incision. ${ }^{6}$ Blood vessels should be ligated and cut while 
clamping. In cases of complete placenta percreta with hematuria, opening the bladder lumen is helpful. Even if the placenta comes out of the uterus wall, bleeding inside the uterus is predominant. Therefore, the separating procedure should be performed without hesitation. After the bladder is separated, the anterior vaginal wall should be cut, and the uterus then excised ( - Fig. 12).

\section{Tips and Warnings}

Separation of the bladder should be performed quickly because bleeding can become massive. If the tissue is separated bluntly by pushing it with the tip of Cooper's scissors, the tissue may be torn, leading to bladder injury. The area to be separated should be tensed and cut sharply with an electric cautery device. The bladder should be pinched and elevated manually, and separated from the uterus employing an electric cautery device. The blood vessels identified should be held with Kelly's clamps, and then cut and ligated.

\section{Tips and Warnings}

In cases of placenta percreta in which the placenta completely invades the bladder, the bladder should be opened, and partially excised while leaving the area of the penetration attached to the uterus. We have experienced several bladder injuries in cases in which the bladder was separated with excessive force. The injured part should be sutured in two layers by simple interrupted suture with 3-0 absorbable thread. After suture, physiological saline containing indigo should be infused into the bladder to check for leakage. The bladder balloon should be retained for 1 week postoperatively.

\section{Closure of the Vaginal Canal and Hemostasis}

Bleeding from the bladder separation surface is often severe, and the bleeding area should be sutured and reinforced with 3-0 absorbable thread in a covering manner. If the bladder lumen is open, double layer suture should be used. The vaginal wall should be closed by $Z$ suture or simple ligation. Because blood flow of the external iliac artery system via the cardinal ligament is extremely abundant, strict hemostasis is necessary.

\section{Drain Insertion and Bdominal Closure}

After intraperitoneal irrigation, a drain should be placed in the Douglas pouch. The pelvic peritoneum may be left open. An adhesion preventing material such as Seprafilm should be applied to the pelvic floor and under the abdominal wall, and the abdominal incision wound should then be closed.

\section{When the Presence of Placenta Accreta/Increta/Percreta Is Unclear or when a Definitive Diagnosis Is Not Obtained}

When the Blood Vessels around the Myometrial Scar Are Engorged

If there is an abundance of engorged blood vessels around the myometrial scar in cases with prior cesarean section, there is no need to incise the lower uterine segment. Considering the need for readiness to suture in case of bleeding from the placental separation surface, a transverse incision in the uterine body, a J-shaped incision, or a longitudinal incision in the uterine body for delivery of the fetus is recommended. A transverse incision in the uterine fundus is used when the uterus is excised while leaving the placenta in situ in cases in which a diagnosis of placenta accreta/increta/percreta has been obtained.

When the Placenta Does Not Separate Spontaneously When the myometrium is pulled together or is concave at the time of pulling the umbilical cord, it is highly likely that placenta accreta/increta/percreta is present. If there is no bleeding, the placenta may be left in situ to complete the operation, or hysterectomy may be performed. If a sufficient blood supply ready for transfusion is not available, there is no need to separate the placenta forcibly. When the placenta is left in situ, blood flow in the placenta should be followed by color Doppler examination, and a decision should be made as to whether the uterus is to be preserved or delayed total hysterectomy should be performed. If the placenta is separated partially and thereby causes bleeding, the placenta should be separated manually. Compression sutures may often achieve hemostasis in cases of partial placenta accreta/increta/percreta. ${ }^{2,8-10}$

\section{Precautions for Avoiding Complications}

\section{Ureteral Injury}

It is recommended that a ureter stent be inserted preoperatively. A specialist in gynecologic tumors with good knowledge of pelvic anatomy should be asked to participate. Obstetricians should actively participate in gynecologic operations, particularly radical hysterectomy, etc., and should be familiar on a regular basis with pelvic anatomy, that is, the positional relationships between the uterus and surrounding organs such as the ureter, bladder, and rectum, and the courses of blood vessels in the deep part of the pelvis. It is also necessary to understand the frequent sites of ureteral injury. ${ }^{6}$

\section{Postoperative Bleeding}

\section{Vaginal Cut End}

The vaginal wall in pregnancy is edematous and thick, and likely to cause ligature loosening. $Z$ suture, and continuous suture should be avoided because they are more likely to become loose, rather than being fastened. Blood flow into the uterus in pregnancy is extremely abundant because of the 
supplies from not only the internal iliac and ovarian arteries but also the external iliac, inferior mesenteric, sacral, and lumbar arteries, etc. Arterial anastomosis is abundant between branches of the internal iliac artery and with other arteries. In particular, in placenta previa accreta/increta/ percreta, there is extremely abundant blood inflow from the external iliac artery system via the vaginal wall, paracolpium, and cardinal ligament. Therefore, postoperative bleeding, if any is present, frequently occurs from the cut end of the vagina. Particular caution is necessary in cases of dilutional coagulopathy due to heparin use or massive hemorrhage.

\section{Site of Vascular Ligation}

Postoperative bleeding is common at the site of focused ligation such as at the sites of uterine artery and vein ligation, the proper ligament of the ovary, or the cardinal ligament. Arterial ligation and focused ligation should always be performed by double ligature. Kobayashi's ligation is useful for ligation of the proper ligament of the ovary. ${ }^{6}$

\section{Complication of Disseminated Intravascular Coagulation}

In cases with a bleeding tendency where dilutional coagulopathy due to massive hemorrhage is predicted, fresh frozen plasma (FPP) should be infused in increments of 5 units while performing pressure hemostasis with towels on the oozing area. At the same time, the patient should be tested for the blood coagulation system, such as the fibrinogen level and prothrombin time (PT), and FFP should be administered to maintain the fibrinogen level at $150 \mathrm{mg} / \mathrm{dL}$ or more. ${ }^{4,10,11}$ Administration of 10 units of FFP elevates the fibrinogen level by approximately 60 to $80 \mathrm{mg} / \mathrm{dL}$. At night, when coagulation tests are not feasible, total protein should be measured, and FFP should then be administered to achieve a level of $4 \mathrm{~g} / \mathrm{dL}$ or more. ${ }^{2,10,11}$

\section{Tips and Warnings}

Massive hemorrhage may occur from the uterine os during the hysterectomy procedure. Because bleeding from the vagina may be overlooked due to the surgical drape, it should be ensured that circulating nurses monitor the amount of blood not only in gauze or the suction bottle but also in the bucket or on the floor.

Conflict of Interest

None declared.

\section{References}

1 Takeda S, Murayama Y. Cesarean hysterectomy for placenta previa accreta spectrum. In: Konishi I, Hiramatsu Y, Sakuragi N, Takeda S, eds. OGS NOW, No. 9. Surgery for Pregnancy with Placenta Previa and Placenta Accrete: Careful Preparation and Critical Management (in Japanese). Tokyo: Medical View; 2012:122-133

2 Takeda S, Takeda J, Makino S. Cesarean section for placenta previa and placenta previa accreta spectrum. Precision surgery in obstetrics and gynecology. Surg J 2020. Doi: 10.1055/s-0039-3402036

3 Kuromaki K, Takeda S, Seki H, Kinoshita K, Maeda H. Indication and efficacy of autologous blood transfusion for pregnant women. J Obstet Gynaecol Res 2002;28(03):182-183

4 Takeda S, Makino S, Takeda J, et al. Japanese clinical practice guide for critical obstetrical hemorrhage (2017 revision). J Obstet Gynaecol Res 2017;43(10):1517-1521

5 Takeda J, Makino S. Temporary arterial balloon occlusion for obstetrical field. In: Takeda S, Kuwatsuru R, eds. Gynecologic and Obstetric Prophylactic Hemostasis by Intra-arterial Balloon Occlusion. Singapore: Springer; 2018:33-39

6 Takeda S. Cesarean hysterectomy. In: Konishi I, Hiramatsu Y, Sakuragi N, Takeda S, eds. OGS NOW,No.2. Mastering the essential surgical procedures; Total abdominal hysterectomy (in Japanese). Tokyo: Medical View; 2010:122-133

7 Pelosi MA III, Pelosi MA. Modified cesarean hysterectomy for placenta previa percreta with bladder invasion: retrovesical lower uterine segment bypass. Obstet Gynecol 1999;93(5 Pt 2):830-833

8 Makino S, Tanaka T, Yorifuji T, Koshiishi T, Sugimura M, Takeda S. Double vertical compression sutures: a novel conservative approach to managing post-partum haemorrhage due to placenta praevia and atonic bleeding. Aust N Z J Obstet Gynaecol 2012;52 (03):290-292

9 Takeda S, Takeda J, Makino S. A minimally invasive hemostatic strategy in obstetrics aiming to preserve uterine function and enhance the safety of subsequent pregnancies. Hypertens Res Pregnancy 2019;7(01):9-15

10 Takeda J, Makino S, Takeda S. Hemostasis for massive hemorrhage during cesarean section. In: Schmolzer G, ed. Cesarean Delivery. IntechOpen; 2019

11 Takeda J, Takeda S. Management of disseminated intravascular coagulation associated with placental abruption and measures to improve outcomes. Obstet Gynecol Sci 2019;62(05):299-306 